which aid identification. Structural formulae abound and there is a clearly marked section on treatment of poisoning for each plant.

This volume is a practical one, designed to help quick and easy identification of poisonous plants and, except for one page, is concerned with human not animal poisoning. Fungi are considered to be outside the scope of the book but a number of Dieffenbachia are included, an important practical addition.

Should we be concerned about poisonous plants when only two deaths have been reported between 1962 and 1978 in Britain? Clearly the answer must be yes ornamental "non-British" plants such as

because 20,000 enquiries were made at the National Poisons Information Service centres, and there were up to 60,000 plantpoisoning cases of children in Germany. Furthermore, there is not just concern over yew and laburnum but also increased public interest in herbal medicines. Both books take careful stock of such medical plants as comfrey and mistletoe, making balanced judgements on the pros and cons of taking such medication, and are, overall, two lovely productions which were a pleasure to review.

J.D. Phillipson is Professor of Pharmacognosy at The School of Pharmacy, University of London.

\section{Talk of plants}

\section{C.A. Stace}

The Penguin Dictionary of Botany.

Edited by Stephen Blackmore and

Elizabeth Toothill.

Penguin: 1984. Pp. 390. Hbk f12.95; pbk £3.95. In the United States The Facts on File Dictionary of Botany (Facts on File, $h b k$ \$21.95).

Longman Illustrated Dictionary of Botany.

By Andrew Sugden.

Longman: 1984. Pp. 192. £3.95, \$7.95.

SPECIALIZED jargon is one of the more daunting obstacles to the understanding of a technical subject, and that of plant biology poses particularly severe problems - many separate disciplines are involved, and the subject has been accumulating technical terms for over 2,000 years. There would be little use to working scientists or students for an encyclopaedic listing of every term that has ever been coined. Hence the main difficulty for the compilers of desk-top dictionaries is to find a middle way; their products must be small enough to be manageable yet large enough to be informative. These two books both strike the right balance.

The Penguin Dictionary of Botany (hereafter Penguin) contains "over 3,000" entries, compiled by ten contributors under a general and a consultant editor, while Longman's offering has "over 1,200" compiled by a single author. The audience for the two books differs, but with some overlap. Penguin is quite sophisticated and will appeal widely to sixth formers, undergraduates (especially) and to the professional plant biologist. Longman is more elementary and will find its greatest use at the school-university interface.

The main feature of Longman is the large number of colour illustrations (averaging more than one per page), and the grouping of terms into 24 subject sections, necessitating a separate index at the end of the book. Penguin, by contrast, is entirely alphabetical and carries relatively few illustrations, most of which are charts and formulae, and some of which are rather unnecessary (over half a page for chlorophyll lamellae, for example). Important ment; there is, for instance, almost an entire page devoted to the chloroplast, excluding the illustration. In each book the cross-referencing is excellent.

Both the dictionaries seek to cover more or less the whole range of "botany", including bacteria and viruses, except that agriculture and horticulture as well as plant biotechnology seem to be omitted by Longman. The latter scores, however, by its inclusion of useful appendices on Greek and Latin prefixes and SI units. Both books would have profited from more appendices on topics such as the periodic table, a system of classification and so on.

Criticisms of omissions must be very subjective, but Longman seems to include rather too much classical terminology (e.g. polyadelphous) at the expense of more modern aspects (e.g. plasmid). Errors of fact, however, are less disputable, and I was disappointed to see a major error perpetrated on p. 47 of Longman. Here crossing over is shown (unequivocally in multicolour) to occur at the position of a chiasma, that is genetic crossing over is said not to occur until after chiasma formation, whereas the reverse has been known to be the case for over half a century. Such misinformation is potentially harmful in an often-misunderstood though essentially elementary topic. Seeking reassurance, I turned to the corresponding entries in Penguin, and found, by implication, the same mistake. These are certainly points requiring urgent rectification at the first opportunity.

How successful these dictionaries will prove will become clear only after trial periods with the intended users. But my general impression is that much thought and attention have gone into both, and that both should (and deserve to) become well used.

C.A. Stace is Reader in Plant Taxonomy and Head of the Department of Botany at the University of Leicester. entries are given a more extended treat-

\section{Order in mammals}

\author{
Malcolm C. McKenna
}

Orders and Families of Recent Mammals of the World.

Edited by S. Anderson and J. K. Jones, Jr. Wiley: 1984. Pp. 686. f63.55, \$54.95.

CHARACTERIZING and keeping track of the taxonomic hierarchy of thousands of genera of mammals distributed among about $\mathbf{3 0}$ orders is no easy task, as a succession of classifiers since Linnaeus has found out. In 1967 the editors of the present volume published Recent Mammals of the World; now they have updated and retitled it. As before, about 20 highly qualified contributors, some inherited from the first project, cover all living mammalian orders and the constituent families in a reasonably uniform style but with a range of originality.

Each still-living order is given a diagnosis, followed by short synopses of current distribution, geological range and a list of constituent families; there is also a section of remarks in each case. Then the format is followed again at the family level. Unfortunately many of the diagnoses contain characters that are merely descriptive, not diagnostic, but they are still useful.

A separate, well-written and generally succinct account is given of fossil mammals, including groups without living members. The known diversity of extinct mammals is increasing rapidly, mainly through the efforts of palaeontologists using screen-washing methods. This is especially true of small rodents and insectivores, but also applies to other orders. Since the 1967 compilation the number of known fossil genera of rodents alone has doubled, surpassing for the first time the number of living genera of rodents.

Among the accounts of living mammals, five chapters on rodents, one on bats, and one on monotremes and marsupials are outstanding, reflecting the enormous amount of recent work in those areas of mammalogy. The original scholarship displayed means that purchase of the book will be a necessity for many palaeontologists.

The illustrations consist mainly of distribution maps, but a number of figures of animals show enough anatomical detail to be helpful in identification (although some have been reduced excessively). Most of the anatomical illustrations are of the skeleton or skull, but dental patterns are not emphasized. An especially valuable feature of the book is the bibliography; the references occupy almost a hundred pages, and many of them are new since the 1967 edition.

Malcolm C. McKenna is Frick Curator in the Department of Vertebrate Paleontology, American Museum of Natural History, New York. 